\title{
Seroprevalence and Risk Factors of Brucellosis among Camels Belonging to Selected Districts of Afar, Ethiopia: Need for Public Awareness
}

\author{
Fikru Gizaw ${ }^{1}$, Gizachew Fentahun ${ }^{1}$, Semu Mersha ${ }^{2}$, Hailegebriel Bedada ${ }^{1}$, \\ Mahendra Pal ${ }^{3,4, *}$, Venkataramana Kandi ${ }^{3,4, *}$ \\ ${ }^{1}$ College of Veterinary Medicine, Samara University, Samara, Ethiopia \\ ${ }^{2}$ Fisheries and Animal Resources Development Bureau, Hetosa District, Oromia, Ethiopia \\ ${ }^{3}$ Narayan Consultancy on Veterinary Public Health and Microbiology, Anand,India \\ ${ }^{4}$ Prathima Institute of Medical Sciences, Nagunur, Karimnagar, Telengana, India \\ *Corresponding author: palmahendra@gmail.com; ramana_20021@rediffmail.com
}

\begin{abstract}
Brucellosis is a highly infectious bacterial disease of global significance, which affects humans as well as a wide variety of animals. A cross-sectional study was conducted in three selected districts of Afar region of Ethiopia to determine the seroprevalence of camel brucellosis. A total of 245 camels from selected districts were included in the study. All serum samples were tested and screened serologically using Rose Bengal plate test and confirmed using a complement fixation test. Associated risk factor analysis was also conducted using chi-square and logistic regression analysis. As a result, 30 (12.2\%) were Rose Bengal plate test reactors in which 10 (4.1\%) were confirmed to be positive using complement fixation test. The statistical analysis indicated that herd size $(\chi 2=13.206$; $\mathrm{p}=0.001$ and $\mathrm{OR}=17.053 ; 95 \% \mathrm{CI}=1.988-146.254)$, contact with other ruminants $(\chi 2=13.524 ; \mathrm{p}=0.00$ and $\mathrm{OR}=12.774 ; 95 \% \mathrm{CI}=1.560-104.625)$ and history of abortion $(\chi 2=28.022 ; \mathrm{p}=0.00$ and $\mathrm{OR}=38.000 ; 95 \% \mathrm{CI}=4.694-$ 307.657) were statistically significant and the major risk factors for the presence and transmission of the disease between animals. But age, body condition score, physiological status, parity and geographical location were found statistically insignificant $(\mathrm{P}>0.05)$. Public awareness towards the diseases was interviewed with the structured questionnaire format and it was noted that most of the pastoralists had no knowledge about zoonotic disease transmission, consequences of consuming raw milk, and handling aborted animals without any protective material. In general, camel brucellosis is prevalent in this area of study and public awareness towards zoonotic importance is low. Therefore, fruitful and sustainable work is required from the government, animal health professionals, and other stakeholders in the prevention and control of the disease. Improved public awareness is inevitable to reduce the prevalence and spread of the camel brucellosis.
\end{abstract}

Keywords: camel brucellosis, complement fixation test, pastoralist, risk factors, rose bengal plate test, seroprevalence, zoonotic importance

Cite This Article: Fikru Gizaw, Gizachew Fentahun, Semu Mersha, Hailegebriel Bedada, Mahendra Pal, and Venkataramana Kandi, "Seroprevalence and Risk Factors of Brucellosis among Camels Belonging to Selected Districts of Afar, Ethiopia: Need for Public Awareness.” American Journal of Microbiological Research, vol. 5, no. 5 (2017): 94-100. doi: 10.12691/ajmr-5-5-1.

\section{Introduction}

Pastoralism is extensively practiced in hot, arid and semi-arid desert regions of Ethiopia, and Ethiopian farmers greatly rely on local livestock for their livelihood [1]. Camels are an important livestock species in the arid and semi-arid zones in Africa and Asia that accounts for $60 \%$ of the land area in Ethiopia and inhabited by pastoralists. 95\% of the 18.9 million camel populations of the world are dromedary camels, which live in Africa, the Middle East and 5\% are Bactrian camels residing in central Asia, China, and Mongolia [2]. 82\% (15.4 million) of the world's camel population is found in the African continent. The camel population of Ethiopia has been estimated to be 2.3 million heads, which places it $3^{\text {rd }}$ in the world next to Somalia and Sudan [2]. Camels contribute significantly to the livelihood of the pastoralists and agropastoralists living in the fragile environments of deserts of Africa and Asia as sources of milk, meat, transportation, leather and wool [3].

Camel production could be a profitable venture for utilizing the vast arid and semi-arid areas of Ethiopia, where other animals survive with difficulty, especially due to the recurring drought conditions. Under such environmental conditions, camels thrive and form a source of milk and meat. But, complete exploration of camels for milk and meat production would only be possible when their reproductive performance is properly understood and improved. Unfortunately, dromedaries are reported to have low reproductive efficiency compared to other domestic species [4]. 
Brucellosis is a re-emerging bacterial zoonotic disease of high economic and public health importance, prevalent throughout the world [5,6]. Brucellosis is still endemic in countries of the Mediterranean basin, the Middle East and Central Asia [5,7]. Camel brucellosis is widely prevalent among African countries such as Ethiopia, Eritera, Somalia and Sudan. Brucellosis is caused by Gram-negative coccobacilli belonging to the genus Brucella. They are short, non-motile, aerobic, facultative intracellular bacteria [8]. Previous research has revealed that the ability of Brucella to replicate and persist in host cells could be directly associated with its capacity to cause persistent disease and to circumvent innate and adaptive immunity [9].

In the pastoral and agro-pastoral areas of Ethiopia, brucellosis has been noted to be endemic causing infections in cattle, camels and other small ruminants [10,11,12]. Although endemic in nature in many developing countries, brucellosis remains under diagnosed and under-reported [13]. Prevalence of brucellosis in Ethiopian camels has not been extensively investigated in comparison with those of other domesticated animal species. It was observed that brucellosis can be transmitted among cattle, sheep, goats, camels and other species [7]. Camels were found to be at greater risk of developing brucellosis, especially when they were in contact with infected large and small ruminants [7].

Brucellosis can generally cause significant loss of productivity in camels through late first calving age, long calving interval time, low herd fertility and comparatively low milk production [7, 14]. Moreover, it should be noted that human brucellosis represents a major public health hazard, which can affect social and economic development in various countries. Human brucellosis is commonly referred to as undulant fever or Malta fever or Mediterranean fever [8]. It is an important occupational zoonosis of livestock handlers, abattoir workers, veterinarians and dairy farmers $[12,15]$. Currently, over five-lakh cases of human brucellosis are reported annually the world wide [13].

In Ethiopia, various surveys have been carried out on the prevalence of brucellosis on livestock in different regions of the country by various investigations. However, the detailed status of brucellosis and its associated risk factors are not thoroughly studied in camels' particularly in Afar regional state and information is so far scanty. Therefore, the objectives of this study were to determine the seroprevalence of camel brucellosis, to assess the associated risk factors for camel brucellosis and to also to know the public awareness towards zoonotic importance of diseases in the study area.

\section{Materials and Methods}

\subsection{Study Area}

Afar regional state is in the Great Rift Valley, comprising semi-arid range land in Northeastern Ethiopia. According to regional estimates, the livestock population of Afar is about 10.12 million and out of this, comprising of 2336488 heads of cattle, 4267969 goats, 2463632 sheep, 852016 camels and 187287 equines that support the region and contributes to the national economy [16].The annual temperature and rainfall in the region is $30-50{ }^{0} \mathrm{C}$ and $200-600 \mathrm{~mm}$, respectively. The altitude of the region ranges from 100-1000 meter above sea level. It is located at $8040^{\prime} 13^{\prime \prime}$ to $14027^{\prime} 29^{\prime \prime} \mathrm{N}$ and 390 51' 13" to $42023^{\prime}$ 03" E latitude and longitude, respectively. The Afar Regional State has five administrative zones, which are further subdivided into 32 districts. Pastoralism and agropastoralism are the two major livelihood ways practiced in the region. The population of the region is estimated to be about 1.5 million of which $90 \%$ are pastoralists and $10 \%$ agro-pastoral [17].

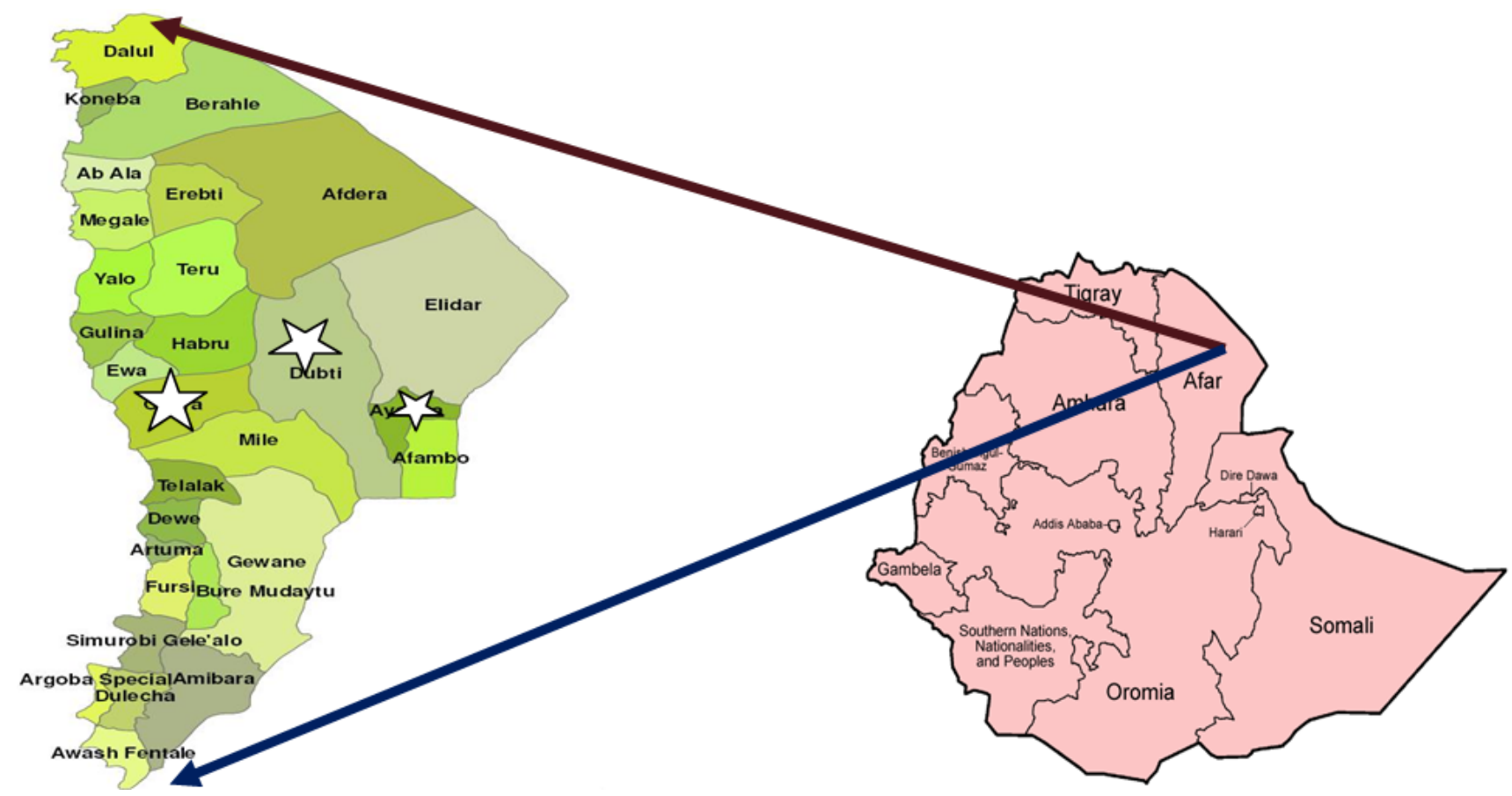

Figure 1. Geographical map of the selected study district in afar regional state, Ethiopia [17] 


\subsection{Study Animals}

The study populations were dromedary type (Camelus dromedaries) camels kept under extensive husbandry which allows free browsing. Camel's age, herd size, body condition score, herd composition, physiological status, history of abortion and parity were recorded.

\subsection{Sampling Method and Sample Size Determination}

Camels were sampled using a combination of multistage and simple random sampling to select peasant associations (PAs), villages and herd. The zone and woredas (they are the third-level administrative divisions of Ethiopia) were selected purposefully based on camel abortion outbreak history, camel population, and willingness of pastoralists and accessible to vehicles. Three districts (Aysaita, Chifra and Dubti) from the zone, four PAs from the woredas, and three herds from each PAs and maximum ten (proportional allocation) camel from each respective herd was included as the study population. The total numbers of camels were proportionally sampled from all districts. Accordingly, a total of 245 camels (100 camels from Chifra, 87 camels from Aysaita and 58 camels from Dubti) were included in this study.

The sample size for this study is determined by the following formula given by Thrusfield (2007) [18]. $n=\left[1.96^{2} \operatorname{Pexp}(1-P \exp )\right] / d^{2}$, Where: $n=$ sample size, Pexp $=$ minimum expected prevalence, $1.96=$ the value of $\mathrm{Z}$ at $95 \%$ confidence interval $\mathrm{d}=$ desired accuracy level at 95\% confidence interval. Therefore, by using the above formula and taking the previous prevalence of $4.1 \%$, the minimum sample size at $95 \%$ confidence interval and at $5 \%$ precision or accuracy level, the sample size was calculated to be 61 [6]. This study included 245 samples, around four times more than the calculated sample size to increase the significance.

\subsection{Study Design}

A cross-sectional study design was conducted from November 2016 to April 2017 by using serological tests, the Rose Bengal plate test and complement fixation test to determine the prevalence of Brucella infection in camels in the selected districts and to identify the potential risk factors associated with the sero-positivity.

\subsection{Study Protocol}

\subsubsection{Blood Sample Collection}

Approximately 6 to $8 \mathrm{ml}$ of blood sample was collected from the jugular vein of each camel using plain vacutainer tubes. The collected blood samples could clot at room temperature and serum was separated from clotted blood by decanting to plastic cryo-vials. A separated serum was stored at $-20^{\circ} \mathrm{C}$ for further serological testing in the National Veterinary Institute (NVI).

\subsubsection{Serological Test}

Two types of serological tests were employed as a screening and confirmatory test for the detection of Brucella antibody: The Rose Bengal Plate Test (RBPT) and the Complement Fixation Test (CFT), respectively.

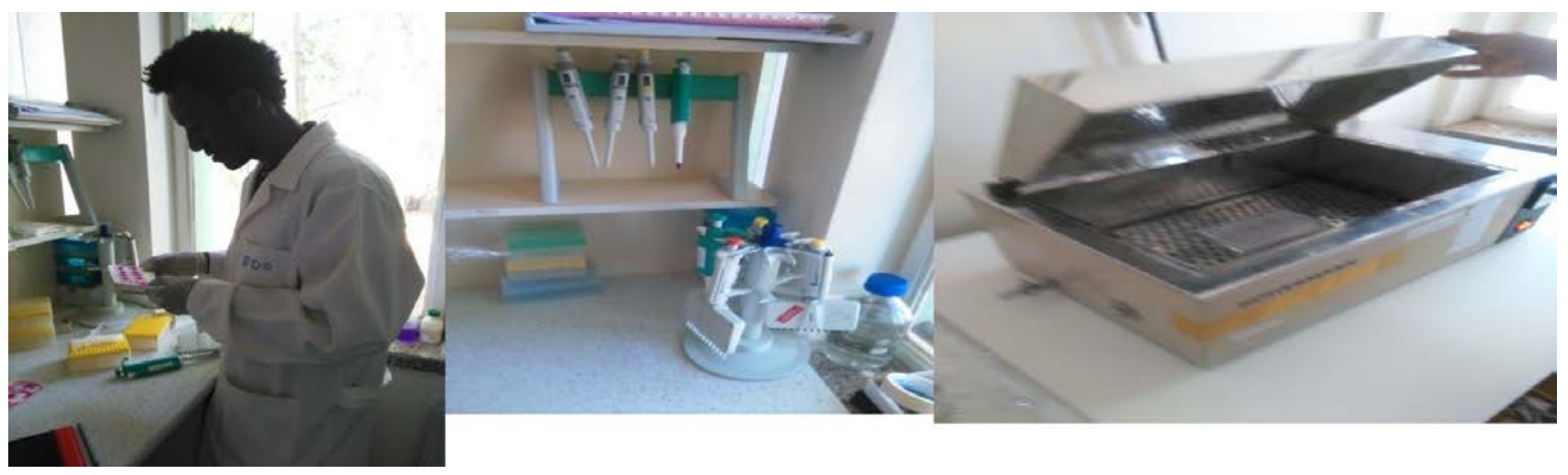

Figure 2. Images of NVI Serology laboratory

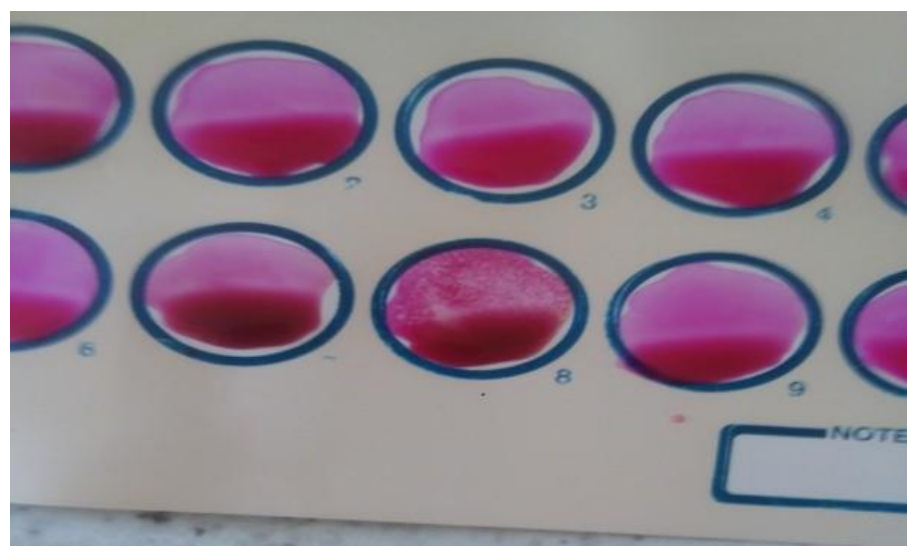

Figure 3. Image showing rose Bengal precipitation test (RBT) result 


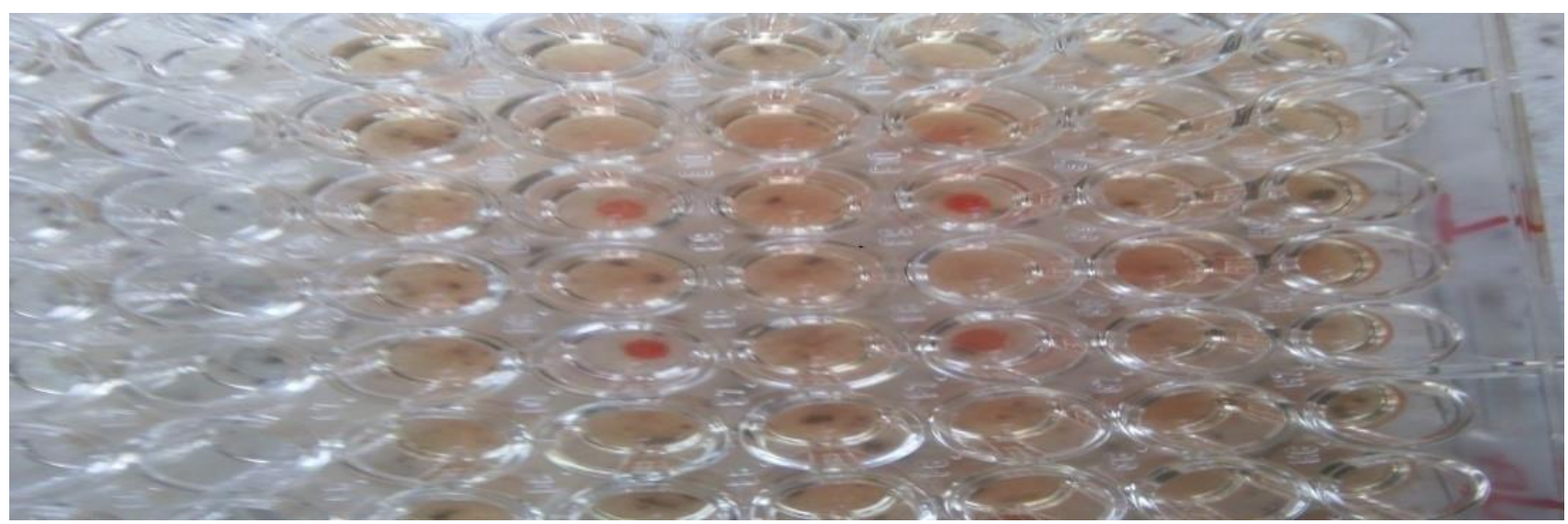

Figure 4. Image showing complement fixation test result

\subsubsection{Rose Bengal Plate Test (RBPT)}

The RBPT is a rapid agglutination test effective in diagnosing brucellosis. It is used as a screening test on the serum samples collected for the presence of Brucella agglutinins. The results were interpreted according to the presence and degree of agglutination. Samples with no agglutination (0) were recorded as negative, while those with + (weak reactive), ++ (reactive), and +++ (strong reactive) were recorded as positive as shown in Figure 3. The test was conducted as described previously by other authors [19].

\subsubsection{Complement Fixation Test (CFT)}

Sera tested positive by RBPT was further confirmed using CFT. The complement systems consist of a series of protein that, if triggered by an antigen antibody complex, react in a sequential manner to cause cell lysis. The test has two steps. The first step is antigen; test serum and complement are mixed and incubated. The second step is an indicator system that consists of sheep red blood cells (SRBC) and an amboceptor that sensitizes red blood cells to the action of the complement. If the test serum contains antibodies to Brucella, an antigen-antibody complex is formed; the complement is used up, and no lysis of SRBC occurs. If the test serum does not contain Brucella antibodies (negative reaction), the complement will not be fixed and lysis of CRBC would occur as shown in Figure 4 [20].

\subsubsection{Questionnaire Survey}

Verbal consent was obtained from the respondents, and the objectives of the survey were explained to them before the start of the interview. The interviews were conducted in the local language (Afarigna). Two questionnaire formats, one for the serum sampled individual animal history and the other with a structured questionnaire format for the herders, was developed and used in this study. The questionnaire focused on animal husbandry and housing practices, knowledge about zoonotic diseases, the habits of animal product consumption and handling, and dead-animal/aborted fetus disposal practices. In total, 45 pastoralists 15 from each district whose animals tested for brucellosis were interviewed. In doing so, the risk factors that have possible associations with the occurrence of brucellosis were investigated and used to support the serological results. The collected data were tabulated, classified and further categorized for systematic and suitable statistical analysis.

\subsection{Data Analysis}

The data collected through questionnaires and laboratory results of the collected samples were entered into Excel databases and analyze using the SPSS software package (SPSS 20.0 for Windows 7, SPSS Inc, Chicago, Illinois). Descriptive statistics such as percentages, proportions and frequency distributions were applied to compute some of the data or were used to describe the nature and the characteristics of the data. The seroprevalence was calculated as the number of serologically positive samples divided by the total number of samples tested.

The difference between the effects of some risk factors on prevalence was analyzed using the Pearson chi-square $(\chi 2)$ test. Logistic regression analyses were used to assess the strength of association and were also calculated to quantify the association of different risk factors with the prevalence of Brucellosis disease. A statistically significant association between variables was said to exist if the calculated P-value is less than 0.05 and if the $95 \%$ confidence interval (CI) for OR doesn't include 1.

\section{Results}

\subsection{Prevalence and Distribution of Camel Brucellosis in Zone 1 Afar}

In this study, out of 245 camels examined 30 (12.2\%) were positive on RBPT screening test. but, on further confirmation by CFT only 10 camels (4.1\%) were seropositve to Brucella infection. Therefore, the true prevalence of camel brucellosis in the selected pastoral area was $4.1 \%$ (Table 1 ).

\subsection{Association between Some of the Risk Factors WITH Occurrence of Brucellosis}

The prevalence of brucellosis seems higher in Dubti (6.9\%) than Assyita (3.4\%) and Chifra (3.0\%) but the difference was statistically insignificant $(\chi 2=1.562 ; \mathrm{P}=0.458)$ (Table 2). Table 2 shows that risk factor at animal level herd size, herd composition and history abortion were found statistically significant $(\chi 2=13.206 ; p=0.001, \chi 2=13.524$; $\mathrm{p}=0.00, \chi 2=28.022 ; \mathrm{p}=0.00$, respectively) while age, body condition score, physiological status, parity and geographical location were found not statistically significant. 
Table 1. Prevalence and distribution of camel brucellosis in Zone 1 Afar

\begin{tabular}{|c|c|c|c|c|c|c|c|}
\hline \multirow{2}{*}{$\frac{\text { District }}{\text { Dubti }}$} & No.tested camel & Positive (inRBPT) & \multicolumn{2}{|l|}{ prevalence } & \multicolumn{2}{|c|}{ Positive (in CFT) } & prevalence \\
\hline & 58 & 9 & \multicolumn{2}{|l|}{$15.5 \%$} & \multicolumn{2}{|l|}{4} & $6.9 \%$ \\
\hline Chifra & 100 & 11 & \multicolumn{2}{|l|}{$11.0 \%$} & \multicolumn{2}{|l|}{3} & $3.0 \%$ \\
\hline Assayita & 87 & 10 & \multicolumn{2}{|l|}{$11.5 \%$} & \multicolumn{2}{|l|}{3} & $3.4 \%$ \\
\hline Total & 245 & 30 & \multicolumn{2}{|l|}{$12.2 \%$} & \multicolumn{2}{|l|}{10} & $4.1 \%$ \\
\hline Variables & Category & $\begin{array}{c}\text { No. } \\
\text { tested }\end{array}$ & $\begin{array}{c}\text { Positive (\%) } \\
\text { RBPT } \\
\end{array}$ & $\begin{array}{l}\text { Positive } \\
\text { (\%)CFT }\end{array}$ & $\mathrm{X}^{2}$ & $\begin{array}{c}\mathbf{p}- \\
\text { value }\end{array}$ & OR(95\%CI) \\
\hline \multirow{3}{*}{ District } & Dubti & 58 & $9(15.5 \%)$ & $4(6.9 \%)$ & \multirow{3}{*}{1.562} & \multirow{3}{*}{0.458} & \\
\hline & Chifra & 100 & $11(11.0 \%)$ & $3(3.0 \%)$ & & & \\
\hline & Assaiyta & 87 & $10(11.5 \%)$ & $3(3.4 \%)$ & & & \\
\hline \multirow{3}{*}{ Age } & Young(< 4years) & 32 & $3(10 \%)$ & $1(3.1 \%)$ & \multirow{3}{*}{2.271} & \multirow{3}{*}{0.321} & \\
\hline & Adult(4-10 years) & 179 & $21(11.7 \%)$ & $6(3.4 \%)$ & & & \\
\hline & Old(>10years & 34 & $6(17.6 \%)$ & $3(8.8 \%)$ & & & \\
\hline \multirow{3}{*}{$\begin{array}{l}\text { Body } \\
\text { condition }\end{array}$} & Poor & 81 & $13(16.0 \%)$ & $4(4.9 \%)$ & \multirow{3}{*}{0.228} & \multirow{3}{*}{0.892} & \\
\hline & Medium & 80 & $8(12.0 \%)$ & $3(3.8 \%)$ & & & \\
\hline & Good & 81 & $7(8.6 \%)$ & $3(3.7 \%)$ & & & \\
\hline \multirow{5}{*}{ Parity } & No parity & 32 & $3(9.4 \%)$ & $1(3.1 \%)$ & \multirow{5}{*}{2.983} & \multirow{5}{*}{0.561} & \\
\hline & $1^{\text {st }}$ parity & 61 & $5(8.2 \%)$ & $1(1.6 \%)$ & & & \\
\hline & $2^{\text {nd }}$ parity & 57 & $5(8.8 \%)$ & $2(3.5 \%)$ & & & \\
\hline & $3^{\text {rd }}$ parity & 60 & $11(18.3 \%)$ & $3(5.0 \%)$ & & & \\
\hline & $4^{\text {th }}$ and above & 35 & $6(17.1 \%)$ & $3(8.6 \%)$ & & & \\
\hline \multirow{3}{*}{ Herd size } & $<20$ & 108 & $10(9.3 \%)$ & $1(0.9 \%)$ & \multirow{3}{*}{13.20} & \multirow{3}{*}{0.001} & $3.640(0.372-35.609)$ \\
\hline & $21-30$ & 93 & $7(7.5 \%)$ & $3(3.3 \%)$ & & & 17.053(1.988- \\
\hline & $>30$ & 44 & 13(29.5\%) & $6(13.6 \%)$ & & & 146.254) \\
\hline \multirow{3}{*}{$\begin{array}{l}\text { Herd } \\
\text { composition }\end{array}$} & Camel alone & 99 & $4(4.0 \%)$ & $1(1.0 \%)$ & & & $1.338(0.082-21.741)$ \\
\hline & Camel and bovine & 75 & $4(5.3 \%)$ & $1(1.3 \%)$ & 13.52 & 0.001 & $12.774(1.560-$ \\
\hline & Camel, bovine and small ruminant & 71 & $22(31.3 \%)$ & $8(11.4 \%)$ & & & 104.625) \\
\hline History of & No & 191 & $8(4.2 \%)$ & $1(0.5 \%)$ & 28.02 & 0.000 & 38.000(4.694- \\
\hline abortion & Yes & 54 & $22(40.7 \%)$ & $9(16.7 \%)$ & 20.02 & 0.000 & 307.657) \\
\hline & Pregnant & 73 & $9(12.3 \%)$ & $4(5.5 \%)$ & & & \\
\hline Physiological & Dry & 101 & $14(13.9 \%)$ & $2(2.0 \%)$ & 1.940 & 0.379 & \\
\hline & lactating & 71 & $7(9.9 \%)$ & $4(5.6 \%)$ & & & \\
\hline
\end{tabular}

Prevalence of camel brucellosis in animal level and associated risk factors were analyzed by using chi-square test $\left(\mathrm{X}^{2}\right)$ and binary logistic regression test analysis for statistically significant variables to measure the degree of association as shown in Table 2.

Camels kept in herds which had $>30$ camels were 17.053 times $(\mathrm{OR}=17.053 ; \quad 95 \% \quad \mathrm{CI}=1.988-146.254)$ higher at risk for Brucella infection than the herd's size of $<20$ camels. Camels, which had kept together with small and large ruminants were12.774 times (OR=12.774; 95\% CI=1.560-104.625) higher at risk for Brucella infection than camel alone. According to camel herder's information, she-camels had a history of abortion were 38.000 times $(\mathrm{OR}=38.000 ; 95 \% \quad \mathrm{CI}=4.694-307.657)$ higher at risk of contracting Brucella infection than she camels with no history of abortion.

\subsection{Results of Questionnaire Survey}

Forty-five animal owners were interviewed as input for serological testing sample and assessing public awareness towards diseases and zoonotic importance with associated risk factors. It was observed that $80 \%$ Afar pastoralists kept different species of animal along with a camel. Moreover, the mixing of the different species during migration, at watering or in night enclosures (resting), between camels and small ruminants was recorded. 100\% of the respondents consumed raw milk and in the Afar pastoralist traditionally, it is not applicable at all to boil camel milk, and all the 45 respondents said they never boiled camel milk. Ninety percent of the animal owners had no awareness about zoonotic importance. Abortion material and other excreta were handled with bare hands, and they do not destroy these materials.

\section{Discussion}

Previous serological surveys in Ethiopia showed that camel brucellosis is an endemic and widespread disease in Ethiopia [6,21,22,23,24,25]. In this study, the overall seroprevalence of camel brucellosis in selected districts recorded was $12.2 \%$ by the RBPT and $4.1 \%$ by CFT. The true prevalence of $4.1 \%$ recorded in the present study 
agrees with the results recorded by Teshome et al. (2003) in Borena with a prevalence of $4.2 \%$ and Hadush et al. (2013) in the Afar with a prevalence of $4.1 \%[6,21]$. However, the result of this study was higher than the observation recorded by Mohammed et al. (2011) in Dire Dawa (1.6\%), Tilahun et al., 2013 in Jijiga and Babile districts, Eastern Ethiopia (2.43\%) and Zeru et al. (2016) in the Afar $(2.09 \%)[23,25,26]$. Our study result was noted to be lower than the observation by Zewolda and Wereta (2012) and Sisay and Mekonnen (2012) who reported a prevalence of $5.7 \%$ and $7.6 \%$, respectively in different districts of Afar region [22,27]. Our results were found to be significantly lower when compared to a study by Musa et al., 2008 in Darfur, Western Sudan, who reported a prevalence of $23.8 \%$ [28]. Such increased prevalence rates could be due to variations in topography, and management system. The results of the present study were between $1.6 \%$ and $7.6 \%$, similar to those observed by other studies from Ethiopia. This may be due to the unpredictable nature of the environmental condition of pastoral and agro-pastoral area of arid, semi-arid, and drought resulted stress, and reoccurrence of disease contributes to fluctuation of prevalence.

Age was classified as young ( $<4$ years), adult (4-10years) and old $(>10)$ according to most previous survey and based on sexual maturity with modification of addition old age by asking owners to see the distribution of diseases in each age group. Accordingly, young she-camels examined 32 with seropositivity of $1(3.1 \%)$, adult she-camels examined 179 with seropositivity of 6(3.4\%) and old she-camels examined 34 with seropositivity of $3(8.8 \%)$. This indicates that more seropositivity to camel brucellosis was seen in adults and old than young camels as it is a disease of sexually matured animals. Hence, the presence of seropositive breeding males and she-camels were considered as risk factors playing a role in the transmission of the disease to other animals [29]. Although no statistically significant difference $(\mathrm{P}>0.05)$ was observed between each age groups, slightly higher seroprevalence was found in those groups with age of greater than 4 years than those groups with age of less than 4 years . Sexually matured animals are more prone to Brucella infection than sexually immature animals since sexually matured animals are at risk of infection and diseases transmission due to sexual mating and sugar erythritol development, which favors the multiplication of pathogen [7].

Body condition of the camels was considered in this study to see the distribution of the infection in different body condition scores since underfed animals are expected to have a poor body condition that is manifested by decreased immunity against various infections [7,30]. even though, in this study body condition score was statistically not significant $(\mathrm{P}>0.05)$, high seropositivity was found in camels with poor (4.9\%) and medium(3.8\%) body condition score than camels with good (3.7\%) body condition score.

Herd size was highly statistically significant associated with brucellosis in camels $(\mathrm{P}=0.01)$. This is in accordance with the findings of Bekele (2004) and Zewolda and Wereta (2012) in Borena and Afar, respectively and Adugna and co-workers (2013) in Afar [22,29,31]. As herd size increases, the chance of contact between animals increases leading to more chances of infection particularly during calving and abortion.
Herd composition (contact with other ruminant) in the present study, there was highly statistically significant difference $(\mathrm{P}=0.001)$ in the prevalence of the disease in the camel population which had contact with other ruminants. It increases the chance of brucellosis transmission from other infected ruminants to dromedary camels. The results of our study goes parallel with the findings of Adugna et al.(2013) and Zeru et al. (2016) in Afar and Tassew and Kassahun, 2014 in Mehoni District, South Eastern Tigray, Ethiopia [23,24,29].

The seropositivity of she-camels with the history of parity with $3^{\text {rd }}$ and $4^{\text {th }}$ were $5 \%$ and $8.6 \%$, respectively which is slightly higher than those with $2^{\text {nd }}, 1^{\text {st }}$ and no parturition (3.5\%,1.6\% and 3.1\%) respectively. But here was no statistically significant association $(\mathrm{P}=0.561)$ between parity and the seroprevalence of the disease. Therefore, this is consistent with the previous study by Hadush et al. (2013); Zewolda and Wereta (2012) in Afar and Tassew and Kassahun, 2014 in Mehoni District, South Eastern Tigray, Ethiopia [6,22,24].

Physiological status showed no statistically significant difference $(\mathrm{P}=0.379)$ in this study and also in accordance with the findings of Hadush and co-investigators (2013) in Afar. In this study, lactating and pregnant camels were found higher (5.6\% and 5.5\% respectively) in seropositivity than dry (2\%) consistent with scientific view since pregnant and lactating camels more prone to stress and immune suppressed than dry and concentration of sugar erythritol contributes to variation in seropositivity [7].

In this study history of abortion was concerned and found highly statistically significant difference $(p=0.000)$ that having history abortion is 38 times more associated with the brucellosis than with no history of abortion this implies the most classical symptoms of brucellosis in camels is abortion [28]. This finding also in accordance with the finding of Zeru et al. (2016) in Afar, even though, the statistical significant difference is very high in this finding [23]. This happened due to selection of study districts with history abortion.

\section{Conclusion and Recommendations}

Brucellosis is a widespread zoonotic disease, with increased interest among veterinarians. It is closely associated with public health and economic concern in many developing countries including Ethiopia .The results of this study revealed that camel brucellosis is widespread and established in pastoral areas of Afar, including the three camel rearing districts. The associated risk factors contributing to the presence and transmission of the disease from animal to animal were age, body condition, herd size, contact with other ruminants, parity, history of abortion and physiological status. However, according to the statistical analysis, the major risk factors for the transmission of the disease from camel to camel included large herd size, contact between large and small ruminants and having history of abortion. Moreover, higher seropositivity was recorded in sexually mature and old, pluriparous, pregnant, and lactating camels which contributed for transmission of the disease. Poor management practices, mixing with other animals and unrestricted movement of camels were thought to support spread of the disease in the study area. 
Lack of awareness about brucellosis together with existing habit of raw milk consumption and close contact with animals may exacerbate the zoonotic importance.

Therefore, based on the above conclusion we recommend that improved management practices and strategic plans should be developed to minimize the chance of contact between animals at different situations. Public health education should be given on modern animal husbandry and disease prevention techniques. Public awareness should be given on the economic and zoonotic importance of the disease. Further investigation on the zoonotic importance, economic impact and etiology of diseases to molecular level should be conducted. Adequate brucellosis control programs in small ruminants would contribute to the reduction of the disease prevalence in camels. Adequate veterinary service should be established in the lowland area pastoral community.

\section{Acknowledgements}

The authors are very thankful to Samara University, Ethiopia for allocating grant to conduct this study and also the camel owners for their cooperation during the collection of samples.

\section{Conflict of Interest}

Nil.

\section{Research Grant}

Work was done under Samara University Thematic Research.

\section{References}

[1] Rota, A. and Sperandini, S. (2009). Livestock and pastoralists, Livestock Thematic Papers Tools for project design, available at www.ifad.org/lrkm/index.htm, accessed at August 11, 2011. Pp.18.

[2] Tezera, G., Nura, D., Hirsi, A. and Mohammed, S.A. (2010). Camel keepers in Ethiopia at a glance, Pastoralist forum Ethiopia, Endogenous livestock development FAO international technical conference on animal genetic resources, 1-7 August 2007, Interlaken, Switzerland. pp. 1-9.

[3] Gwida, M., El-Gohary, A., Melzer, F., Khan, I., Rösler, U. and Neubauer, H. (2012). Brucellosis in Camels. Res. Vet. Sci., 92: 351-355.

[4] Hermans, S. (2009). Genetic and environmental factors affecting camel heifer's reproduction. Second conference of the international society of camelid research and development. Abstract, Djerba, Tunisia. P. 172

[5] Saegerman, C., Porter, S. and Humblet, MF. (2008). Risk assessment of the re-emergence of bovine brucellosis/tuberculosis. A Paper Presented to International Colloquiumon Emerging Animal Diseases, From Science to Policy, 17 October 2008, Brussels, Belgium.

[6] Hadush, A. and Pal, M. (2013). Brucellosis. An important re-emerging bacterial zoonosis of global importance. Inter. J. Livestock Research 3. 28-34.

[7] Radostits, M., Blood, C. and Gay, C. (2007). Veterinary Medicine: A text book of the disease of cattle, sheep, goats, pigs and horse. $10^{\text {th }}$ ed. Bailliere Tindall. London, pp. 984-988.

[8] Pal, M. (2007). Zoonoses. $2^{\text {nd }}$ Ed. Satyam Publishers, Jaipur, India.
[9] Fichi, T. A. (2003). Intracellular survival of brucella: defining the link with persistence. Vet. Microbiol., 92: 213-223.

[10] Yimer, E., Ali, A., Mesfin, A., Deressa, A. and Girmaye, T. (2008). Brucellosis as a zoonosis in Chifra district, Afar regional state, Ethiopia. Bull Anim. Health. Prod. Afric., 56: 336-357.

[11] Hadush, A., Pal, M., Tesfu, K. and Zeru, F. (2013). Sero-epidemiology of camel brucellosis in the Afar region of Northeast Ethiopia. Acad. J., 5: 269-275.

[12] Pal, M., Lemu, D., Worku, S. and Desta, G. (2016). Seroprevalence study of bovine brucellsois and reproductive problems in small dairy farms of North Shewa, Ethiopia. Int. J. Livestock Res. 6: $1-10$.

[13] Donev, D., Karadzovski, Z., Kasapinov, B. and Lazarevik, V. (2010). Epidemiological and Public Health aspects of Brucellosis in the Republic of Macedonia. Sec. Biol .Med. Sci., 1: 33-54.

[14] Wernery, U. and Kaaden, O. (2002). Infectious diseases of Camelids. Blackwell Science Inc. London, pp. 99-116.

[15] Pal, M., Tesfye, S. and Dave, P. (2013). Zoonoses occupationally acquired by abattoir workers. J.Environ.Occup.Sci.2: 155-162.

[16] CSA (2010). Federal Democratic Republic of Ethiopia. Central Statistical Agency, Agricultural Sample Survey Report on Livestock and Livestock Characteristics. Volume II, 2009/10. Statistical bulletin 468, Addis Ababa, Ethiopia.

[17] CSA (2014). Agricultural sample Survey 2013/14 (2006 E.C.): Volume II. Report on livestock and livestock characteristics (private peasant holdings). Federal democratic republic of Ethiopia Central Statistical Agency (CSA). Statstical Bulletin 573. August, 2014, Addis Ababa, Ethiopia. Pp. 188.

[18] Thrusfield, M. (2007). Veterinary Epidemiology $3^{\text {rd }}$ ed. London. Blackwell Science Ltd. Pp: 227-247.

[19] Amanuel, T., Getachew, T., Tesfu, K. and Nigatu, K. (2015). Seroprevalence and risk factors of Brucellosis in small ruminants slaughtered at Beshoftu and Modjo export abattoirs, Ethiopia. 9:373-380.

[20] ESGPIP (2009). Estimation of weight and age of sheep and goats. Ethiopian Sheep and Goat Productivity Improvement Project. Technical Bulletin, No. 23.

[21] Teshome, H., Molla, B.andTibbo, M. (2003). A seroprevalence study of camel brucellosis in three camel-rearing regions of Ethiopia. Trop. Anim. Health Prod., 35:381-389.

[22] Zewolda,S.andWereta, M. (2012). Seroprevalence of Brucella infection in camel and its public health significance in selected districts of Afar region, Ethiopia. J. Environ. Occupat. Sci., 1: 9198.

[23] Zeru, F., Gebrezgabher, W., Dessalegn, K., Tilahun, S., Guben, Y., Mohammed, H. and Hadush A. (2016). Prevalence and Risk Factor of Brucellosis in Dromedaries in Selected Pastoral Districts of Afar, Northeastern Ethiopia. J Natu Sci Res.6:2224-3186

[24] Tassew, H. and Kassahun, F. (2014). Sero-Epidemiological Study of Camel Brucellosis in Mehoni District, South Eastern Tigray, and Ethiopia. J. Microbiol. Res., 4: 18-23

[25] Tilahun, B. Bekana, M., Belihu, K. and Zewdu, E. (2013). Camel brucellosis and management practices in Jijiga and Babile districts, Eastern Ethiopia. J. Vet. Med. Anim. Health, 5: 81-86.

[26] Mohammed, O., Megersa, B. and Abebe, R. (2011). Seroprevalence of brucellosis in camels in and around Dire Dawa City, Eastern Ethiopia. J .Anim .Vet. Adv., 10: 1177-1183.

[27] Sisay, W. and Mekonnen, H. (2012). Seroprevalence of brucella infection in camel and its public health significance in selected districts of afar region, Ethiopia. J. Environ. Occup. Sci., 1: 91-98.

[28] Musa, M.. and Shigidi, M.. (2001). Brucellosis in camels in intensive animal breeding areas of Sudan: Implications in abortions and early-life infection. Revue. Elev. Med. Vet. Pays. Trop., 54: 11-15.

[29] Adugna, W., Sisay, T. and Keskes, S. (2013). Camelus dromedarius brucellosis and its public healthassociated risks in the Afar National Regional State in north eastern Ethiopia. Acad. Vet. Sci., 55:89.

[30] Faye, B. and Bengoumi, M. (2006). Assessment of body condition and body composition in camel by barometric measurements. $J$. Camel Pract. Res., 13: 67-72.

[31] Bekele, M. (2004). Sero-epidemiological study of brucellosis in camels (Camelus dromedarius) in Borena lowland pastoral areas, Southern Ethiopia. MSc Thesis. Addis Ababa University, Faculty of Veterinary Medicine, Debre Zeit, Ethiopia. 